Clinical Operational Research Unit, University College London, UK

c.pagel@ucl.ac.uk Follow Christina Pagel on Twitter @chrischirp

Cite this as: BMJ 2021;373:n986 http://dx.doi.org/10.1136/bmj.n986 Published: 19 April 2021

\section{There is a real danger that covid-19 will become entrenched as a disease of poverty}

\author{
We must act now to prevent a further widening in wellbeing between poor and rich
}

\author{
Christina Pagel director
}

Since reaching a height of around 70 ooo confirmed covid-19 cases a day in England at the start of the year, the third lockdown has brought cases down to around 2500 a day (at the time of writing). Hospital admissions are back to levels last seen in September 2020, and over half of the adult population has received at least one dose of covid-19 vaccine. We've experienced almost six months of national lockdown in the past year and are just emerging from what has been promised to be the last one.

But while we have all experienced this pandemic together, we have not all had the same experience. Deprived and minority ethnic communities have borne the brunt of the pandemic so far and there is now a very real danger that covid-19 will become entrenched as a disease of poverty.

Those living in deprived communities have been more likely to contract covid-19, with weekly average case rates since September 50\% higher than the least deprived communities (283 per week per 100000 people compared with 184 per week per 100000 people). Compared with the least deprived communities, people in the most deprived areas have had more than double the number of intensive care admissions and almost double the risk of dying, most likely because poverty often goes hand in hand with poorer health and covid-19 risk factors such as obesity, hypertension, and diabetes. ${ }^{1-3}$ As the UK vaccination programme proceeds, we see differential uptake by deprivation there too: Open Safely data to the end of March shows, for instance, that among shielding adults 16-69 years old, $79 \%$ had had one vaccine dose in most deprived communities compared with $92 \%$ in least deprived communities. ${ }^{4}$ The difference in vaccine uptake is most pronounced in minority ethnic communities. ${ }^{5}$

People in more deprived communities are more likely to catch covid-19 for several reasons. Firstly, they are much more likely to have to work outside the home and in roles, such as health and care workers, security guards, public transport workers, cab drivers, and retail. These jobs are all associated with higher exposure to catching covid-19. ${ }^{6}$

Secondly, those in more deprived communities are more likely to live in multioccupancy housing: those living in households with more than six people have twice the risk of infection compared with households with one or two people. ${ }^{6}$ Those in deprived communities have worse access to high quality green spaces which, as we move out of lockdown, is likely to lead to more crowded meetings outdoors or more meetings in higher risk indoor spaces. ${ }^{7}$
Thirdly, many are financially unable to isolate. A recent paper in The BMJ reported that only about $20 \%$ of people with symptoms request a covid test and only about half of those with symptoms isolate. ${ }^{8}$ It identified that being unable to isolate was a key factor in determining both testing and isolation behaviour. Dido Harding, head of test and trace, acknowledged that lack of support for isolation was lowering the effectiveness of contact tracing. ${ }^{9}$ Poor housing further exacerbates the problem as even those who do isolate risk infecting others in their household because of cramped accommodation. Cevik and colleagues argued persuasively that enhancing comprehensive support for isolation is crucial as we exit the most recent wave of infection. ${ }^{10}$

The above three factors have two implications: firstly, that lockdowns are much less effective in deprived communities because more people work outside the home, cannot afford to isolate, and cannot lock down. ${ }^{11}$ Also poorer and more crowded housing means covid-19 continues to propagate more easily. This means that there is significantly more covid circulating in deprived communities as we start coming out of lockdown-almost 2.5 times as many cases per head in the last two weeks of March as in the least deprived areas. ${ }^{12}$ This makes outbreaks much more likely as people start to mix more-particularly with worse access to safer outdoor spaces. And differential vaccine uptake also means that these communities are less protected once outbreaks occur. Even as the rest of the country enjoys a more normal summer, more deprived areas will likely be subject to waves of infections, the burden of ill health (and potentially death) that follows, and local lockdowns restricting local economies-just where growth is needed most. ${ }^{13}$

Secondly, these differences will likely recreate the north-south divide in covid-19 cases and restrictions that we saw last summer and autumn in England as northern regions have substantially more deprived local authorities than the south. ${ }^{14}$ Only one out of the 25 local authorities with the highest case rates is in the south of England.

This scenario is not inevitable. Improved support for self-isolation, as instituted now in Newham, is fundamental: increased population testing will do nothing to prevent infections in people who test positive but cannot isolate. ${ }^{15}$ Work spaces and schools can be supported to improve ventilation to reduce transmission indoors-again, a policy that would disproportionately help those who cannot work from home. Thirdly, gaps in vaccine uptake must be dealt with by working with local communities to tackle vaccine concerns-particularly in the wake of 
concerns about Oxford AstraZeneca vaccine-and to make getting a jab as easy as possible. ${ }^{16}$ The government has touted a "levelling up" agenda for tackling regional inequality in England. They must act now to prevent a further widening in wellbeing between poor and rich, north and south.

$\mathrm{CP}$ is a member of Independent SAGE

Competing interests: none declared.

1 ICNARC. Covid-19 report. www.icnarc.org/Our-Audit/Audits/Cmp/Reports.

2 Williamson EJ, Walker AJ, Bhaskaran K, et al. Factors associated with COVID-19-related death using OpenSAFELY. Nature2020;584:430-6. doi: 10.1038/s41586-020-2521-4 pmid: 32640463

3 Patel JA, Nielsen FBH, Badiani AA, et al. Poverty, inequality and COVID-19: the forgotten vulnerable. Public Health 2020;183:110-1. doi: 10.1016/j.puhe.2020.05.006 pmid: 32502699

4 Open Safely. NHS Covid-19 vaccine coverage. https://opensafely.org/research/2021/covid-vaccinecoverage.

5 Study reveals low covid jab take-up among black people in England. Guardian. 29 March 2021. www.theguardian.com/world/2021/mar/29/study-low-covid-jab-take-up-black-people-england.

6 Riley S, Wang H, Eales O, et al. REACT-1 round 9 final report: Continued but slowing decline of prevalence of SARS-CoV-2 during national lockdown in England in February 2021.medRxiv 2021.03.03.21252856 [Preprint]. 2021. www.medrxiv.org/content/10.1101/2021.03.03.21252856v1.

7 Gray S, Kellas A. Covid-19 has highlighted the inadequate, and unequal, access to high quality green spaces. BMJ Opinion. March 2021. https://blogs.bmj.com/bmj/2020/07/03/covid-19-hashighlighted-the-inadequate-and-unequal-access-to-high-quality-green-spaces.

8 Smith LE, Potts HWW, Amlôt R, Fear NT, Michie S, Rubin GJ. Adherence to the test, trace, and isolate system in the UK: results from 37 nationally representative surveys. BMJ2021;372:n608. doi: 10.1136/bmj.n608 pmid: 33789843

9 Tolhurst A. Dido Harding admits 20000 people a day are ignoring calls by NHS Test and Trace to self-isolate. 3 February 2021. www.politicshome.com/news/article/dido-harding-admits-20000people-a-day-are-ignoring-calls-by-nhs-test-and-trace-to-selfisolate.

10 Cevik M, Baral SD, Crozier A, Cassell JA. Support for self-isolation is critical in covid-19 response. BMJ 2021;372:n224. doi: 10.1136/bmj.n224 pmid: 33504501

11 Jason Strelitz. Twitter. 10 March 2021. twitter.com/strelitz_jason/status/1369679289579409408?s=20

12 Riley S, Eales O, Haw D, et al. React-1 round 10 report: level prevalence of SARS-CoV-2 swab-positivity in England during third national lockdown in March 2021. Imperial College London. 8 Apr 2021. https://spiral.imperial.ac.uk/handle/10044/1/87351.

13 SPI-M-O. Summary of further modelling of easing restrictions: roadmap step II. 31 March 2021. https://assets.publishing.service.gov.uk/government/uploads/system/uploads/attachment_data/file/975909/S1182_SPI-M-O_Summary_of_modelling_of_easing_roadmap_step_2_restrictions.pdf.

14 Lintern S. North at risk of "being left behind" again as covid cases rise and experts warn of new variant threat. Independent. www.independent.co.uk/news/health/covid-cases-north-southlockdown-b1824083.html.

15 Stephen Reicher. Twitter. 6 April 2021. https://twitter.com/ReicherStephen/status/1379482678685282305.

16 Triggle N. Covid: Under-30s offered alternative to Oxford-AstraZeneca jab. 7 April 2021 www.bbc.co.uk/news/health-56665517.

This article is made freely available for use in accordance with BMJ's website terms and conditions for the duration of the covid-19 pandemic or until otherwise determined by BMJ. You may use, download and print the article for any lawful, non-commercial purpose (including text and data mining) provided that all copyright notices and trade marks are retained. 